\title{
O SINCRETISMO SEMIÓTICO DO GÊNERO CHARGE SOBRE AS MANIFESTAÇÕES POLÍTICAS NO BRASIL
}

\section{THE SEMIOTICS SYNCRETISM OF THE GENRE CRITICAL CARTOONS ABOUT THE POLITICAL PROTESTS IN BRAZIL}

\begin{abstract}
Alexandra Pereira Dias ${ }^{9}$ Valéria Vicente Gerônimo ${ }^{10}$

RESUMO: Este artigo tem por objetivo analisar, à luz da semiótica discursiva, como as charges veiculadas na internet descrevem as pessoas, ou seja, no caso, os manifestantes que foram aos protestos ocorridos no Brasil, entre os anos de 2013 e 2016. Esta pesquisa é qualitativa-interpretativista e se utiliza de um corpus constituído por quatro charges que foram veiculadas nas redes sociais durante as referidas manifestações. A metodologia procedeu-se da seguinte forma: após o estudo das categorias propostas pela semiótica discursiva, mais especificamente as categorias de figuras (cromáticas, topológicas e eidéticas) e os temas, recorremos às charges selecionadas, para, enfim, procedermos à análise dos dados. Os resultados apontaram que os textos sincréticos analisados, satirizavam os manifestantes, haja vista que as ações de certos tipos de manifestantes que foram às ruas protestar não condiziam com o discurso que supostamente defendiam. É possível perceber, ainda, que entre os sujeitos que buscam nos protestos alternativas de mudança para resolução dos problemas de cunho social, alguns os utilizam também para demonstrar amor à pátria, ou ainda, como promoção individual.
\end{abstract}

PALAVRAS-CHAVE: Gênero charge. Manifestantes. Protestos. Texto sincrético.

ABSTRACT: This article aims to analyze, through a discursive semiotics perspective, how the critical cartoons posted on the internet describe the people who took part in the political protestsin Brazil between 2013 and 2016. This qualitativeinterpretative research uses a corpus consisting of four critical cartoons that were posted on social networks during the mentioned protests. The methodology was as follows: after the study of the themes and the categories proposed by the discursive semiotics, more specifically the categories of (chromatic, topological and eidetic) figures, the selected cartoons were used in order to proceed to the analysis of the data. The results revealed that the syncretic texts, that is, the critical cartoons, satirized the protesters, once the actions of certain types of protesters who went to the streets to protest did not match the discourse that they supposedly defended. It is also possible to see that among the individuals who seek for alternatives to change social problems through protests, some people also use protests to show love for their homeland, or even for the pursuit of individual promotion.

KEYWORDS: The genre critical cartoon. Protesters. Protests. Syncretic text.

\section{Introdução}

No Brasil, as manifestações populares foram marcadas por importantes movimentos como as "Diretas Já", "Caras pintadas", dentre outros. Nessa última década, especificamente no ano de 2013, após o governo federal autorizar aos Estados e Municípios o aumento das tarifas dos transportes públicos, muitas manifestações ocorreram no país. Foram organizadas pelo movimento "Passe livre" e ficaram conhecidas como "Manifestações dos 20 centavos". Os participantes eram, na ocasião, na maioria, jovens estudantes que, indignados com os aumentos das passagens dos transportes públicos, protestavam nas grandes metrópoles.

Diante da repressão dos policiais contra os estudantes que protestavam de forma pacífica, o movimento ganhou visibilidade e adesão popular, e assim, jovens e adultos foram às ruas em favor, então, não apenas da redução das tarifas dos transportes públicos e contra a

\footnotetext{
9 Mestranda em Linguística pelo Programa de Pós-Graduação em Linguística (PROLING/UFPB). Membro doAteliê de Textos Acadêmicos (ATA/UFPB) e do Grupo de Estudos em Letramentos, Interação e Trabalho (GELIT/UFPB). Endereço eletrônico: alexandradiasuf@gmail.com

${ }^{10}$ Graduada em Licenciatura Plena em Letras, habilitação em Língua Portuguesa, pela Universidade Federal da Paraíba. Endereço eletrônico: valeriavicentejp@gmail.com
} 
coibição advinda dos policiais na ocasião dos protestos, mas, sobretudo, por questões relativas à ausência de educação, saúde, moradia, liberdade de expressão, dentre outros motivos.

Nesse cenário, os jornais de grande circulação noticiavam que "O Gigante acordou". E, assim, diversos movimentos como o "Vem Pra Rua", cujo líder e mentor é o empresário Rogério Chequer ${ }^{11}$, bem como o Movimento do Brasil Livre (MBL), coordenado por Kim Katagiri ${ }^{12}$, tomaram as ruas com reivindicações e palavras de ordem, como: "Não é apenas pelos 20 centavos".

Com os escândalos de corrupção que assolavam o governo da ex-presidente do Brasil, Dilma Rousseff,bem como de governosanteriores, e que persistiram, como os desvios de merenda escolar, verbas públicas e etc., os manifestantes não se calaram e a pressão a favor das investigações de corrupção na Petrobrás, Lava Jato, reverberaram nas ruas. Entre os temas já reivindicados pela população, outros também ganharam destaque nos protestos contra o governo de Rousseff, como: "impeachment", "homofobia", "intervenção militar", "justiça social", e outros, de forma que o perfil dos manifestantes variava na medida em que elencavam novas "causas" ao protestar.

Esses assuntos foram veiculados nos jornais impressos, televisivos e em sites específicos de política, ou ainda, nas redes sociais, de modo que foram alvo de críticas, tanto daqueles que não foram às manifestações, por defenderem que os manifestantes usassem esses protestos para chamar a atenção para causas particulares, quanto daqueles que achavam que o "movimento" não passava de uma estratégia de empresários na tentativa de manipular o povo.

Nessa ocasião, o gênero charge foi bastante utilizado, uma vez que fazia críticas a essa dualidade de opinião da população, bem como de determinados setores da sociedade, a exemplo dos empresários e partidos políticos que não concordavam com a posição assumida pelo governo daquele momento. Diante do exposto, iniciamos essa discussão, questionandonos como as charges abordaram os tipos de pessoas, isto é, os manifestantes que foram às ruas protestar nas cidades brasileiras?

Nessa perspectiva, este trabalho qualitativo-interpretativista analisa, à luz da semiótica discursiva, como as charges, que aqui caracterizamos como textos sincréticos, descrevem as pessoas, ou seja, os manifestantes que foram às ruas protestar. Nesse caso, atentamos para os efeitos de sentido desses textos e seus desdobramentos, a partir dos procedimentos da sintaxe discursiva, das figuras, dos temas e das categorias cromáticas, topológicas e eidéticas. Para tanto, coletamos na internet quatro charges que foram veiculadas nas redes sociais durante as manifestações.

Assim, tomamos como base a Semiótica Discursiva cujas ideias são interpretadas por Diana de Barros (2002); Pietroforte (2004); Teixeira (2008), dentre outros. Após o estudo das categorias propostas pela semiótica, recorremos às charges para, enfim, procedermos à análise dos dados. A hipótese levantada é a de que as charges criticam a legitimidade das manifestações e trazem à tona questões políticas e ideológicas dos participantes que, ao protestarem, desconhecem a realidade do país, haja vista que algumas questões reivindicadas durante os protestos foram motivo de opressão para centenas de brasileiros, a exemplo da ditadura militar, período no qual muitas pessoas foram mortas, e outras exiladas do país, devido à opressão sofrida. Por outro lado, a ideia de analisar esses textos sincréticos surgiu ao percebermos que as charges, embora veiculem humor por meio da linguagem verbal e não verbal, satirizam, criticam, tratam de assuntos políticos e sociais, que podem, de alguma forma, conscientizar o leitor dos eventuais problemas existentes nessas manifestações.

\footnotetext{
${ }^{11}$ Engenheiro e empresário, Rogério Chequer Ramalho Machado é porta-voz do movimento "Vem pra rua", e um dos organizadores das manifestações contra a corrupção ocorridas no Brasil.

${ }^{12}$ Kim Patroca Kataguiri é ex-aluno do Curso de Ciências Econômicas, da Universidade Federal do ABC, neto de imigrantes japoneses e ex-colunista da Folha de São Paulo. É ativista e um dos principais fundadores do movimento MBL.
} 
Este artigo encontra-se dividido em três partes. Afora a introdução e as conclusões, discutimos o gênero charge e suas múltiplas linguagens. Além disso, faremos uma concisa discussão a respeito da noção de gênero e sua prática social fundamentada nos precursores do estudo dos gêneros, Bakhtin (2003) e Marcuschi (2010) ${ }^{13}$, e em Semiótica. Em seguida, apresentamos as categorias topológicas, cromáticas e eidéticas, bem como, categorias de pessoa, tempo, espaço, temas e figuras, para enfim, nos debruçarmos sobre a análise dos textos sincréticos.

\section{O gênero charge e suas múltiplas linguagens}

A charge é um gênero verbo-visual ${ }^{14}$ que contempla diferentes linguagens e que, por meio do humor, faz críticas sobre muitos assuntos de relevância social. Sendo, pois, veiculado em revistas, livros, jornais, sites etc., é um gênero textual híbrido ${ }^{15}$, que possui formas, traços, cores, desenhos, gráficos, constituindo a linguagem visual; e esta cruza com a linguagem verbal, complementando-a. Assim, esse texto vem ganhando grande adesão popular nas redes sociais e na internet de modo geral.

A linguagem verbal, neste gênero, contempla aspectos linguísticos e discursivos que apontam para questões relacionadas a denúncias sociais. A visual, por sua vez, é evidenciada por meio de figuras, cores e traços. Os desenhos em forma de caricatura das personagens chamam a atenção, visto que retratam a figurativização do objeto satirizado. Além disso, as cores podem remeter a aspectos político-partidários, ideológicos, culturais, dentre outros. A temporalidade é outra característica da charge, pois denuncia problemas do cotidiano e, nesse caso, aborda temas que possuem uma problemática atual, que poderão ser compreendidos mais facilmente, a depender do contexto histórico em que os fatos ocorreram.

Como o gênero charge contempla diferentes linguagens, ele é um texto sincrético, pois, segundo Teixeira, é "um objeto que, acionando várias linguagens de manifestação, está submetido, como texto, a uma enunciação única que confere unidade à variação" (2008, p. 10). Conforme ainda a autora, a semiótica discursiva, sobretudo, está interessada pela criação de sentido de um texto através da articulação entre o plano de conteúdo e o plano de expressão, e das categorias gerais de análise que, por um lado, contemplam a totalidade dos textos, expostos em qualquer materialidade e, por outro lado, delimitam as estratégias enunciativas particulares dos textos concretos (2008, p. 6-7).

Bakhtin (2003, p. 262-266), ao discutir sobre a noção de gênero, ressalta que a diversidade dos gêneros do discurso é inesgotável e infinita, pois corresponde à complexidade da atividade humana, possibilitando a heterogeneidade dos gêneros do discurso. Dessa forma, a charge é um gênero complexo porque apresenta "estilo linguístico, funcional e temático relativamente estáveis" (op. cit. 2003, p. 266), sobretudo pela relação recíproca entre linguagem e ideologia.

Diana de Barros (2002, p. 82-83), por sua vez, adverte que as formações ideológicas são sustentadas por meio da enunciação, na escolha dos temas e das figuras, nos procedimentos argumentativos e nas projeções do discurso, no nível das estruturas

\footnotetext{
${ }^{13}$ Não podemos deixar de mencionar a importância do estudo da noção de gênero atribuída à Bakhtin. No Brasil, o nome de Luiz Antonio Marcuschi fixa-se naturalmente quando se trata do estudo do gênero. Em relação ao estudo dos gêneros, esses autores destacam-se, por isso é relevante incluí-los, principalmente na segunda seção deste artigo.

${ }^{14}$ Para Jacques Fontanille, "um gênero seria a reunião de um tipo de texto e de um tipo de discurso, união que produziria 'formas estereotipadas' ou, ainda, 'formas prototípicas' de gênero" (PORTELA; SCHWARTZMANN, 2012, p. 75).

${ }^{15}$ Salientamos que a palavra "híbrido"está sendo utilizada no sentido de conter, neste gênero em especial, múltiplas linguagens.
} 
discursivas. Elimina-se, portanto, qualquer ideia de imparcialidade e de neutralidade do texto, pois, como já afirmava Bakhtin, "um enunciado absolutamente neutro é impossível” (2003, p. 289).

$\mathrm{E}$, como a internet e as redes sociais possibilitam novas formas de comportamento, os gêneros do discurso - conhecidos também como gêneros textuais - se adaptam à comunidade social, à história, a objetivos comunicativos e à cultura. Então, Marcuschi (2010, p. 19-20) reafirma a teoria bakhtiniana, quando declara que "os gêneros são formas sociais de organização e expressões típicas da vida cultural" e acrescenta que a interação online tende a acelerar potencialmente a evolução dos gêneros por ele estar integrado ao meio tecnológico, pela alta participação interativa.

David Crystal (MARCUSCHI, 2010, p. 22) elenca três aspectos em relação ao papel da linguagem na internet e o efeito desta na linguagem, porém realçamos apenas um desses pontos de vista dos gêneros realizados no meio virtual: "a internet transmuta de maneira bastante complexa os gêneros existentes, desenvolve alguns realmente novos e mescla vários outros".

A charge, diferentemente de outros gêneros que são veiculados na internet, como Histórias em Quadrinhos, Cartum, Tirinha, dentre outros, possui linguagem verbal e visual que, ora se contrapõem ora se complementam, e que tem como função não apenas promover o riso ou chamar atenção por meio das figuras em forma de caricaturas, mas trazer à tona questões que merecem destaque e que denunciam, por meio da linguagem, estruturas de poder presentes na sociedade. Para Marcuschi (2010), o gênero reflete estruturas de autoridade e poder muito claras. E, nesse caso, a charge, a nosso ver, é um gênero textual cujo propósito comunicativo pretende desvelar essas ações.

Teixeira (2008) preconiza, ao falar sobre os modos de linguagem, que os textos constituídos de várias linguagens são particularmente desafiadores e, assim, algumas teorias vêm buscando aparatos metodológicos que possam compreendê-los. Entre essas teorias está a semiótica social de Kress e Van Leeuwen e a semiótica discursiva, de origem greimasiana. Nesse caso, ainda conforme a autora, ao usar as denominações de "texto sincrético" ou "sincretismos de linguagem", a semiótica discursiva ressalta não a matéria ou processo, mas o efeito, isto é, o resultado (2008, p. 5).

Nessa perspectiva, para analisar um texto sincrético, é necessário ponderar a estratégia enunciativa "que sincretiza as diferentes linguagens numa totalidade significante" (TEIXEIRA, 2008, p. 10), que pode ser constituída por figuras, temas e outros procedimentos do sujeito da enunciação. Os percursos figurativos e temáticos em textos sincréticos, como a charge, se manifestam por meio das categorias da expressão e do conteúdo. A seguir, discutimos essas categorias e aprofundamos o estudo do sujeito da enunciação e os demais procedimentos enunciativos.

\section{Categorização das figuras e sintaxe discursiva}

As categorias de figuras têm por finalidade organizar os elementos textuais. Conforme Teixeira (2008), são as seguintes: cromáticas, topológicas e eidéticas. Vejamos o quadro abaixo:

Categorias de figuras

\begin{tabular}{|l|l|l|}
\hline \multicolumn{1}{|c|}{ Cromáticas } & Topológicas & Eidéticas \\
\hline Combinações de cores. & Relação das formas. & Posição das formas. \\
\hline
\end{tabular}


Para analisarmos um texto sincrético, utilizamos essas três categorias que culminam nos efeitos de sentido em gêneros verbos-visuais. Dessa forma, a categoria cromática é responsável "pela manifestação por meio da cor", a categoria topológica é averiguada "pela manifestação da distribuição dos elementos figurativizados" voltada para a posição ou ocupação espacial dos atores e a categoria eidética é "a manifestação por meio da forma". Tanto essas categorias temático-figurativas, que revestem o nível narrativo, como os demais procedimentos discursivos configuram em percursos nos níveis fundamental, narrativo e discursivo. Por isso, não se analisa tema, figura e outros elementos isoladamente.

Diana de Barros (2002) explica que a semiótica constrói os sentidos do texto sob a forma de um percurso gerativo do sentido. Para a autora o nível discursivo é o patamar mais superficial do percurso e, nesse caso, o mais próximo da manifestação textual. Sobre as estruturas discursivas, a autora pontua que essas são mais concretas e complexas, isto é, mais "enriquecidas" semanticamente do que as estruturas narrativas e fundamentais. As estruturas narrativas convertem-se em discursivas quando assumidas pelo sujeito da enunciação que, nesse caso, faz escolhas de pessoa, tempo, espaço e figuras, transformando-as em discurso.

As estruturas narrativas são assumidas como valores por um sujeito ou envolvem sujeitos que, através de sua ação, transformam o mundo ou estabelecem contratos ou conflitos característicos das relações humanas. Dessa maneira, é necessário descrever a cena, determinar seus integrantes e o papel que cada um representa no texto. Como o sujeito ${ }^{16}$ investe valor no objeto, a relação desse sujeito pode estar em conjunção (realizado) com o objeto de valor ou em disjunção (não realizado) com ele.

Assim, a enunciação caracteriza-se, em primeira definição, como instância de mediação entre estruturas narrativas e discursivas. E, nesse caso, Barros (2002) defende que é nas estruturas discursivas que a enunciação mais se revela e onde mais facilmente se apreendem os valores sobre os quais, ou para os quais, o texto foi construído. A autora pontua que analisar o discurso é determinar as condições de produção do texto. Desse modo, a semiótica examina as relações entre enunciação e discurso sob a forma de diferentes projeções, entendendo que a enunciação projeta, para fora de si, os actantes e as coordenadas espaço-temporais do discurso, que não se confundem com o sujeito, com o espaço e o tempo da enunciação, procedimento denominando pela autora de desembreagem (2002, p. 54).

Nessa "desembreagem", as categorias de pessoa, do espaço e do tempo são utilizadas. Assim, o sujeito faz várias opções para projetar o discurso, considerando sempre os efeitos de sentido que espera produzir. Nas palavras da autora: "Estudar as projeções da enunciação é, por conseguinte, verificar quais os procedimentos utilizados para constituir o discurso e quais os efeitos de sentido fabricados pelos mecanismos escolhidos" (BARROS, 2002, p. 54). Ainda de acordo com a autora, todo discurso procura persuadir seu destinatário por meio do dizer verdadeiro (ou falso), e tem por finalidade criar a ilusão de verdade. Assim, existem dois efeitos básicos produzidos pelos discursos com a finalidade de convencerem da sua verdade:

\section{$\checkmark$ Proximidade ou de distanciamento da enunciação; \\ $\checkmark$ Realidade ou referente.}

O principal procedimento, de acordo com Barros (2002, p.55), é o de produzir o discurso em terceira pessoa, no tempo do "então" e no espaço do "lá". Duas são as desembreagens que se contrapõe. Vejamos:

$\checkmark$ Desembreagem enunciva: "ele", "lá", "então", que produz efeito de objetividade e
imparcialidade;

${ }^{16} \mathrm{O}$ sujeito semiótico é aquele que quer, ou que deve ou que pode obter o objeto de valor. 
$\checkmark$ Desembreagem enunciativa: “eu", “aqui" e "agora", que produz efeito de subjetividade, parcialidade.

Ao discorrer sobre o enunciador e enunciatário, a autora afirma que ambos são desdobramentos do sujeito da enunciação que cumprem os papéis de destinador e de destinatário do discurso. Além disso, informa que o enunciador define-se como o destinadormanipulador responsável pelos valores do discurso, sendo capaz de levar o enunciatário a crer e a fazer (Cf. BARROS, 2002, 62).

Conforme preconiza a autora, a manipulação do enunciador é exercida como um fazer persuasivo, já ao enunciatário cabe o fazer interpretativo e a ação subsequente. E, nesse caso, a persuasão do enunciador quanto à interpretação do enunciatário é realizada no e pelo discurso. Além disso, no nível das estruturas discursivas é que mais se revelam as relações entre enunciador e o enunciatário.

\subsection{Semântica discursiva}

Os valores assumidos pelo sujeito da narrativa, no nível do discurso, são disseminados sob a forma de percursos temáticos e recebem investimentos figurativos. Desse modo, a disseminação dos temas e a figurativização são tarefas do sujeito da enunciação. Assim, segundo Barros (2002), tematizar um discurso é formular os valores de modo abstrato e organizá-los em percursos. Os procedimentos de tematização são:

$\checkmark$ A organização dos percursos temáticos, em função da estruturação narrativa, subjacente;

$\checkmark$ As relações entre tematização e figurativização.

Esses percursos temáticos, pela definição proposta, resultam da formulação abstrata dos valores narrativos. Além disso, a recorrência de um tema no discurso depende da conversação dos sujeitos narrativos. Conforme destaca Barros (2002, p.72):

a figurativização é a instalação de figuras, ou seja, o primeiro nível de especificação figurativa do tema, se passa do tema à figura: a iconização é o investimento figurativo exaustivo final, isto é, a última etapa de figurativização: com o objetivo de produzir ilusão referencial.

A iconização do discurso diz respeito aos efeitos da realidade, quando se examinam os procedimentos de ancoragem. Barros (2002) diz que na iconização, bem como nas etapas da figurativização, o enunciador utiliza as figuras do discurso para levar o enunciatário a reconhecer, o que a autora destaca como "imagens do mundo". Nesse caso, cabe ao enunciatário crer ou não no discurso. Por outro lado, o fazer-crer e o crer dependem de um contrato de veridicção que se estabelece entre o enunciador e o enunciatário, o qual regulamenta o reconhecimento das figuras. Já os temas se espalham pelo texto e são recobertos pelas figuras.

A reiteração dos temas e a recorrência das figuras no discurso denominam-se "isotopia". Em conformidade com Barros (2002), a isotopia assegura a linha sintagmática do discurso e sua coerência semântica e distingue-se da seguinte forma: isotopia figurativa e isotopia temática. Na busca pelos sentidos do texto, faz-se necessário examinar as relações entre as isotopias, que são denominadas metafóricas ou metonímias (2002, p. 76).

As estruturas fundamentais que são, ainda de acordo com a autora, o ponto de partida da geração de sentido do discurso determinam o mínimo de sentido a partir do qual o discurso 
se constrói. Assim, trata-se da relação de oposição ou "diferença" entre dois termos, no interior de um mesmo eixo semântico que os engloba.

\section{Analisando os dados}

Nosso corpus é constituído por quatro charges que enumeramos de 1 a 4 . Os textos tematizam as pessoas que atuaram nas manifestações que ocorreram no Brasil, entre os anos de 2013 a 2016. Considerando os limites deste trabalho, analisamos de modo mais detalhado as charges 1 e 2, e as charges 3 e 4 de modo mais pontual, por meio das categorias de expressão que são formadas por figuras, temas, categorias cromáticas, topológicas e eidéticas, das categorias de conteúdo que são constituídas pela linguagem verbal, e dos demais procedimentos enunciativos discutidos nas seções anteriores. Após a análise, relacionamos as quatro charges.

\section{Figura 1}

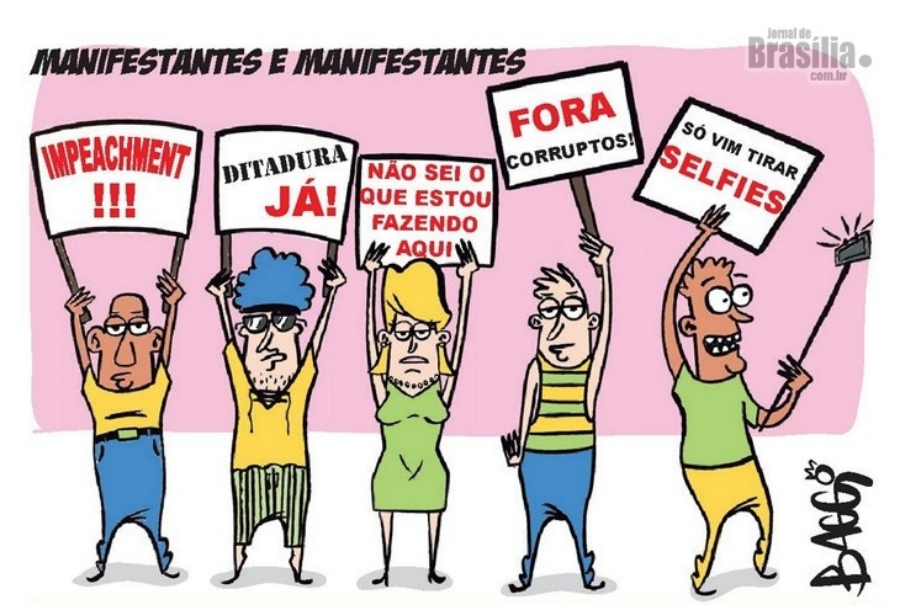

BAGGI, 2015

Disponível em: http://aws.jornaldebrasilia.com.br/charges/380/perfil-dos-manifestantes-brasileiros/

Ao analisarmos a charge acima, percebemos a articulação entre a linguagem verbal e visual. Na parte superior, os letreiros do título "MANIFESTANTES E MANIFESTANTES" chamam a atenção para os tipos de manifestantes que serão apresentados nas figuras. Assim, ao fazer alusão a eles, o enunciador faz menção a dois tipos de pessoas: àquelas que foram às ruas protestar e àquelas que também foram às ruas, mas com propósitos distintos.

Assim, por meio dos enunciados das cinco placas como "Impeachment!!!", "Ditadura Já!", "Não sei o que estou fazendo aqui", "Fora Corruptos!” e "Só vim tirar selfies", encontramos figuras e temas que remontam um cenário das manifestações. Nessa perspectiva, esses temas apontam para questões de cunho político, mas também se referem a assuntos que pouco se relacionam com os protestos, como os temas de "indecisão" e "ślfies". A ruptura dessa coerência torna as ações descritas no texto contraditórias, no entanto, isso também pode ser um procedimento para criar determinados efeitos de sentido, de acordo com a intenção do enunciador.

Para a semiótica, não é importante depreender o tema e a figura isoladamente, mas identificar o(s) percurso(s) temático(s) e o(s) figurativo(s), pois o segundo concretiza o primeiro, que, por sua vez, reveste o nível narrativo.

Observamos que a mulher ao centro é loira que, popularmente, é apontada como "burra" o que é demonstrado pelo cartaz que conduz. A sua direita existe um manifestante extremista que quer a volta da ditadura, e outro que deseja o IMPEACHMENT, sem indicar o motivo. À esquerda um dos manifestantes tem por valor acabar com a corrupção, mas com a mão aberta para traz parece sugerir que espera receber alguma propina. O último à esquerda, não tem compromisso político algum (só aparecer nas redes sociais) embora esteja, 
sugestivamente, virado para a esquerda. É possível perceber que o enunciador destaca que em meio àqueles que buscam alternativas de mudança, pressionando por meio de protestos, também há pessoas que usam as manifestações para se promover, como no discurso "só vim tirar selfies". Além disso, por meio da linguagem não verbal, é possível perceber que as cinco personagens em destaque dão ênfase a diferentes tipos de pessoas. Se por um lado, os temas tratados pelos manifestantes evidenciam a insatisfação com o atual cenário político brasileiro, estabelecendo o sentido de contração, por outro, também é possível afirmar que alguns manifestantes compreendem as manifestações como um meio de descontração. Assim, trata-se da relação de oposição referente à expressão entre contração versus descontração.

No centro da imagem, a figura de uma mulher loira, entre quatro manifestantes do sexo masculino, aponta para possíveis disparidades entre a figura feminina versus masculina. Nesse caso, a figura feminina, em destaque, relaciona-se com o tema mulher. Ademais, uma vez que dentre os quatro manifestantes apenas uma é do gênero feminino, a figura da mulher nas manifestações é estereotipada. Isso indica que apesar de boa parte dos manifestantes não apoiarem a saída da ex-presidente do Brasil do poder, deixaram-se levar pelo preconceito de que mulher não tem competência para liderar um país. Assim, cria-se um efeito de sentido de que o gênero feminino não compreende o atual cenário político brasileiro, e vão às manifestações para serem lideradas, e não para liderar. Além do mais, há mais mulheres do que homens no Brasil, de acordo com o IBGE (Instituto Brasileiro Geográfico e Estatística). Nesse caso, a mulher é censurada por meio do enunciado, de modo que põe em voga um preconceito antigo da sociedade brasileira, de que por ser do sexo feminino, não deve, não quer, não sabe e não pode se posicionar.

$\mathrm{O}$ tema em questão faz menção à retirada da ex-presidente do Brasil, Dilma Rousseff, do posto de presidente. Nessa perspectiva, entendemos que o enunciado "impeachment", que pede a destituição da presidente, remete ao tema da luta entre partidos políticos no Brasil. Assim, por meio das categorias cromáticas, os letreiros das placas erguidas pelos manifestantes contemplam cores como a categorias de expressão, vermelho versus preto e, nesse caso, a categoria fundamental de conteúdo é marcada pelo contraste entre vida versus morte. Isso evidencia que as cores tentam demarcar o fim do governo da presidente Dilma, bem como do partido que esteve à frente do Brasil nessas últimas décadas.

Além disso, a cor vermelha faz menção ao Partido dos Trabalhadores que, ainda na década de 1990, foi responsável por grandes manifestações populares no Brasil. Assim, há uma oposição entre luta versus poder. Por outro lado, as categorias cromáticas encontradas nas cores das roupas dos manifestantes, isto é, verde, amarelo e azul, remetem às cores da bandeira do Brasil. Além disso, o amarelo figurativiza a riqueza, isto é, o dinheiro e, nesse caso, destacamos, nesta charge, a inserção de empresários e de partidos políticos nesses movimentos, que convocam o povo para a "festa da democracia". A oposição fundamental é coletividade versus individualidade.

O enunciado "Só vim tirar selfies", bem como a imagem de um homem se exibindo para uma câmera fotográfica, remete ao tema da cultura do self no Brasil, pois a figura em destaque aponta para a ideia de que, nas manifestações, vários participantes foram às ruas na intenção de registrar o êxito da democracia brasileira, mas também por um momento de promoção individual nas redes sociais. Além disso, a câmera fotográfica remete ao tema da mídia alienante, ou seja, os meios de comunicação que tentam persuadir a população, e se utilizam dessas manifestações para convencer os manifestantes e conseguirem seus objetivos.

Quanto às categorias de espaço, tempo e pessoa, encontramos na linguagem verbal, bem como na visual, um discurso que se situa no espaço do "aqui", "agora", no presente atual. Assim, as charges remontam um cenário de subjetividade e parcialidade por meio do discurso desembreado em primeira pessoa e ao fim demonstram, também, a riqueza dos efeitos de sentido vinculados entre as categorias de expressão e as de conteúdo. No entanto, se observarmos os letreiros escritos, a desembreagem enunciva é destacada pelo "discurso 
objetivo", ou melhor, pelo apagamento da expressividade individual, complementado pela linguagem visual. Já a desembreagem enunciativa é enfatizada pelos letreiros da figura feminina e da personagem se exibindo para uma câmera, em que consideramos a prevalência da expressividade individual, inclusive ao único homem que não está na posição frontal.

Isto posto, apresentamos a categoria fundamental objetividade versus subjetividade. Com efeito, Barros ressalta que "com esse recurso de duas ou mais vozes confundidas, adotam-se perspectivas variadas e, embora cada uma assuma a sua verdade, o texto, no conjunto, consegue relativizá-las" (2002, p. 57). A autora, ainda, enfatiza que esses procedimentos enunciativos produzem efeitos que resultam em sentidos diversos, e que a enunciação nunca é revelada no texto em que se projeta, mantendo-se sempre pressuposta.

Por outro lado, quanto às categorias topológicas, é possível identificar que os cinco personagens presentes na charge se encontram numa mesma posição, isto é, direcionados para frente exibindo os cartazes, com exceção apenas do último personagem que, ao segurar uma câmera fotográfica se dispersa e desvia-se para esquerda. No panorama político brasileiro, o partido da ex-presidente é conhecido como "esquerda", antes e depois do mandato de Dilma e de Lula, e a oposição, como "direita". A categoria fundamental é definida pelo contraste esquerda versus direita. Ao virar-se para a esquerda, o personagem se opõe aos objetivos da manifestação, enquanto na maioria das placas há outro posicionamento. Nesse caso, percebemos que a categoria fundamental é oposição versus posição. Isso explicaria os tipos de pessoas que atuam nessas manifestações e que, de alguma forma, possuem não apenas opiniões adversas, mas comportamentos que não condizem com o que demonstram nas ruas ao manifestarem-se.

A repetição de temas e de figuras no discurso é denominada de isotopia, como dissemos acima. Ela assegura a coerência semântica e oferece a "chave" de leitura do texto. Num mesmo texto podem ocorrer relações entre as isotopias figurativas, pressupondo cada uma delas uma leitura temática, o que leva à descoberta de novas leituras. A apresentação de mais de uma leitura temático-figurativa nos discursos é considerada um discurso pluri-isotópico.

Em suma, essa charge tem mais de um plano temático-figurativo que se imbricam, dentre eles, o da insatisfação com o atual cenário político brasileiro, da mídia alienante, da figura feminina, das intenções dos manifestantes e do patriotismo. Desse modo, essa charge possui um discurso pluri-isotópico.

A $2^{\mathrm{a}}$ charge:

Figura 2

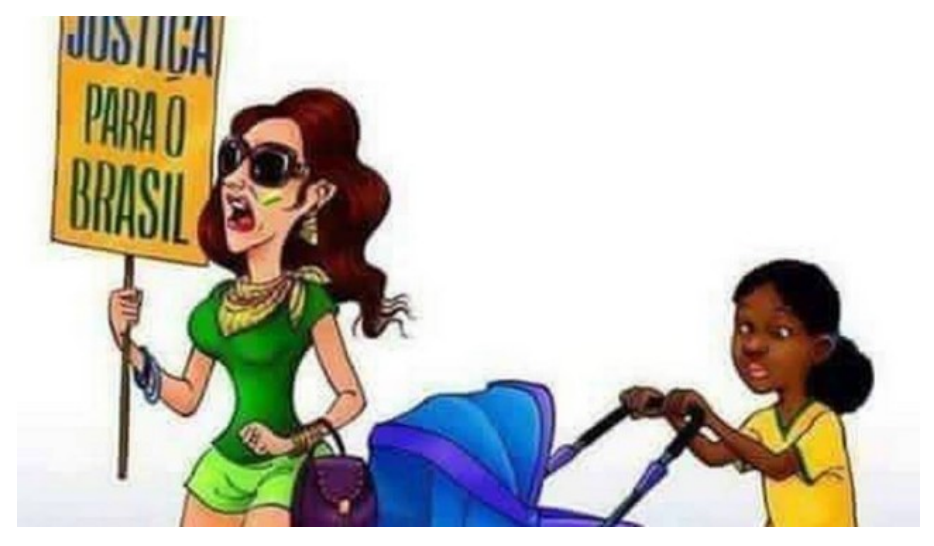

EXTRA.GLOBO, 2016

Disponível em: https://extra.globo.com/noticias/brasil/foto-de-casal-acompanhado-de-baba-em-manifestacao-divide-opinioes-nasredes-18866609.html

A charge acima, igualmente a $1^{\mathrm{a}}$ analisada, remete também ao cenário das grandes manifestações. Nesse texto, o chargista apresenta a imagem de uma mulher e, logo atrás, 
encontra-se uma criança negra que conduz um carrinho de bebê. A mulher bem como a criança estão vestidas com roupas das cores da bandeira do Brasil, sendo que a figura feminina que se encontra à frente está vestida com uma blusa e um short de cores verdes e a criança, que se encontra um pouco atrás, com uma blusa amarela de gola levemente verde.

Os acessórios usados pela mulher são óculos escuros, pulseiras em ambas as mãos, echarpe ao pescoço e uma bolsa de grife. A personagem que se projeta para frente segura uma placa com a mão direita e uma bolsa da cor lilás no braço esquerdo. Os letreiros da placa são verdes e azuis com plano de fundo amarelo e o enunciado destacado na placa pede: "Justiça Social para o Brasil". Nessa perspectiva, a imagem verbal se contrapõe à linguagem visual, a ação da mulher, uma vez que apresenta a cena de exploração infantil. A mulher que luta nas manifestações em favor de justiça para todos brasileiros explora uma criança negra. A figura de uma criança carregando um carrinho de bebê remete ao tema do trabalho infantil e ao trabalho escravo, pois a madame rica e bem vestida tem direito a manifestar-se e portar o cartaz;à babá, uma negra vestida com simplicidade, que se instaura por um dever-fazer (cuidar do bebê), é negada a possibilidade de manifestar-se. Em ambos os casos, nessa instância, segundo o Estatuto da Criança e do Adolescente (ECA), é proibido qualquer trabalho a menores de quatorze anos de idade. Assim, a figura da mulher com uma placa, direcionando-se às manifestações em busca de justiça social, traz à tona a questão dos perfis de pessoas que foram a esses protestos reivindicar e os tipos de motivação que tiveram. Em relação ao tema trabalho escravo, os negros eram escravizados, sem direito a questionar e a se contrapor, foram perseguidos, torturados, enfim, tratados como "animais", ou pior, como "objetos". A figura da babá representa o proletariado, que mesmo sendo remunerado, deve estar à disposição da patroa "elite" mesmo contra a vontade. Percebemos que há uma oposição entre justiça versus injustiça no nível discursivo, já no nível fundamental, teríamos vida versus morte. Isso evidencia a incoerência já elencada na $1^{\mathrm{a}}$ charge entre Manifestantes e manifestantes.

As categorias cromáticas, isto é, verde, amarelo e azul, que remetem às cores da bandeira brasileira, apresentadas na $2^{\mathrm{a}}$ charge, recobrem o tema da desigualdade social. Ao observarmos a figura da mulher vestida de verde, essa cor representa o tema da esperança, porém essa cor na camisa da criança é imperceptível, embora o amarelo, que designa riqueza, seja abundante nela, configura outra contradição entre as categorias de expressão e das categorias de conteúdo. Nesse caso, as cores evidenciam que os mesmos manifestantes não têm as mesmas oportunidades e, nesse caso, a imagem da criança pobre e negra faz um contraponto com a da mulher rica e branca. Nesse ponto, realçamos a oposição dessa categoria, que mescla com a topológica e a eidética, inferioridade versus superioridade.

$\mathrm{Na}$ imagem, a mulher desloca-se à frente da criança com o carrinho de bebê, deixando ambos para trás, recobrindo-as completamente. Nesse sentido, no texto sincrético, por meio da categoria topológica, é possível afirmar que há um abismo que separa, em termos econômico e social, as duas figuras femininas, isto é, a mulher e a criança, estabelecendo a oposição frente versus atrás. A mulher é bem mais alta do que a criança, o que remete às categorias alto versus baixo, que remonta a ideia de igualdadeversus desigualdade. Quanto à categoria de pessoa, ao usar o verbo no presente do indicativo, o enunciador deixa transparecer que existe uma ilusão de aproximação e de igualdade, produzindo os efeitos de objetividade e imparcialidade assumidos pela mulher.

Salientamos também que, apesar da linguagem verbal se contrapor à visual, delineiamse múltiplos planos temático-figurativos por meio da isotopia do trabalho infantil, da isotopia do trabalho escravo e da isotopia da justiça. Esse discurso pluri-isotópico possibilita várias leituras, pois elas se relacionam, resultando nos efeitos de sentido expostos neste artigo. 


\section{Figura 3}

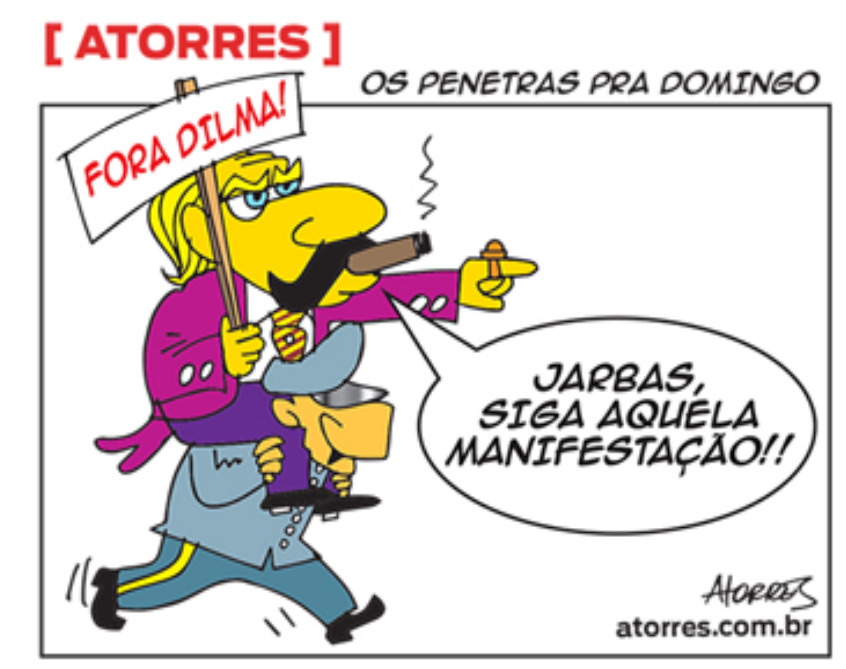

TORRES, 2016

Disponível em: https://www.facebook.com/search/top/?q=http\%3A\%2F\%2

Fdiogenesbrandao.blogspot.com.br\%2F2016\%2F03\%2Fa-charge-da-manifestacao.html

$\mathrm{Na}$ charge acima, "Os penetras pra domingo", evidencia-se, por meio da linguagem visual, um empresário de gravata com um charuto na boca. Nas mãos carrega uma placa, cujo enunciado defende o "Fora Dilma". Além disso, o empresário que está sendo carregado nas costas por um suposto motorista, aponta com o dedo indicador a direção da manifestação por meio da linguagem verbal: "Jarbas, siga aquela manifestação!!”. Nesta perspectiva, a linguagem verbal versus visual se complementam, na medida em que o empresário, ao tentar se infiltrar nas manifestações, se contradiz diante da postura autoritária e incoerente apresentada ao ser levado nas costas por alguém subserviente. Nesse caso, idealiza nas manifestações a oportunidade de tomada de poder. Além do mais, o empresário, ao apontar o dedo para a esquerda, tem como alvo perseguir os manifestantes "da esquerda" que reivindicam por melhorias, para oprimir, pois, como sabemos, houve manifestações contra e a favor do governo de Dilma. Neste cenário, o motorista que o leva nas costas, figurativiza o domínio dos empresários que, revestidos de riqueza e poder, utilizam pessoas como escravas, na tentativa de realizar os seus desejos. Além disso, as figuras como charuto, bigode, paletó e o anel remetem aos temas de poder e autoridade. Esses objetos usados pelo "empresário" foram utilizados, por décadas, como um símbolo de riqueza e poder da burguesia brasileira e, assim, apenas os mais ricos e abastados tinham acesso a eles.

Nas categorias cromáticas, identificamos que tanto o empresário como o motorista não estão vestidos com as cores da bandeira brasileira, o que tematiza, por meio das figuras, a deterioração da pátria. Além disso, observamos que o empresário é destacado por várias cores enquanto no motorista permanece a gradação das tonalidades cinza, resultando na oposição luminosidade versus opacidade. Outro problema é a inserção de empresários e de partidos políticos nesses movimentos, o que evidencia que essas manifestações não se apresentam como legítimas da população, conforme demonstrado pelas mídias que as divulgaram.

No que se refere as categorias topológicas, temos a oposição (conflito) entre patrão e empregado. O primeiro é quem determina a direção a ser tomada. Ao segundo cabe, tão somente, obedecer. O patrão está em uma posição superior, ou seja, montado em cima do empregado que o carrega com dificuldade. Para o patrão a saída de Dilma era importante, tendo em vista que é do partido dos trabalhadores. No tocante às categorias eidéticas que dão destaque às formas, nesse nível, o homem com curvas mais largas é levado nos ombros por outro homem de formas menos arredondadas. $\mathrm{O}$ tema remete as decisões governamentais que 
são tomadas nas altas instâncias, mas que precisam, de algum modo, do apoio popular por meio das manifestações.

Em síntese, identificamos como planos temático-figurativos: o poder autoritário, a repressão por parte dos empresários, a deterioração da pátria e a desigualdade social. Enfatizamos que pode haver outros planos temático-figurativos, embora esses que já citamos consideramos os mais salientes.

\section{Figura 4}

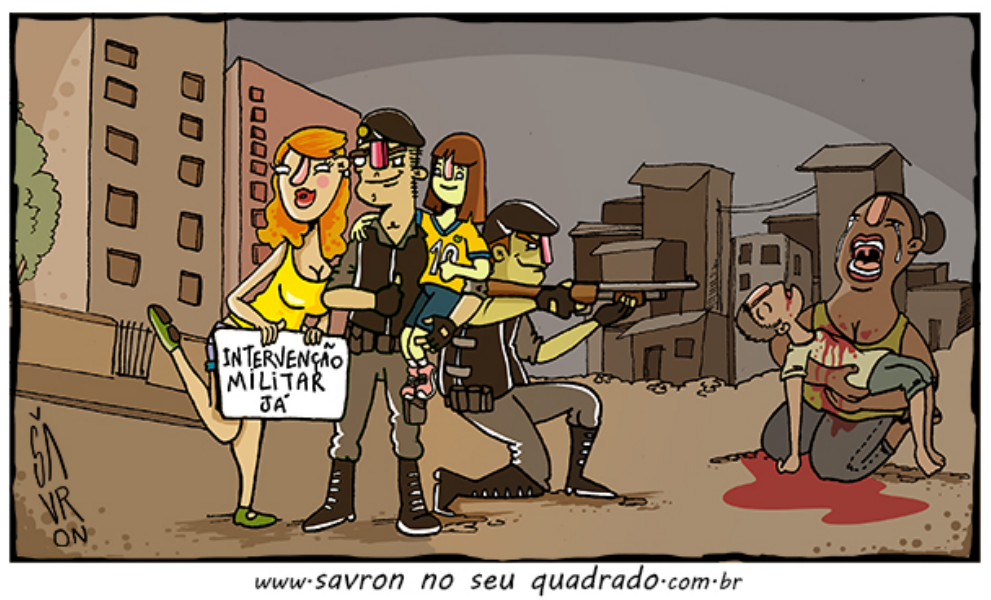

SAVRON, 2015

Disponível em: https://expressaodoambiente.wordpress.com/category/politica/page/2/

A charge em questão aponta para duas cenas que merecem destaque. Ao lado esquerdo da imagem, junto aos prédios, o militar fardado com uma criança nos braços, pousa para uma foto juntamente com uma mulher magra e loira. Nas mãos, a mulher segura um cartaz que pede "Intervenção militar já". Além disso, as cores, ou seja, amarelo, verde e vermelho são as cores fortes, em oposição da cor cinza e marrom do cenário. A cena seguinte, que acontece do lado da imagem, reconstitui um militar atirando com uma espingarda em uma criança que se encontra no colo de uma mulher negra e gorda, e que, aos prantos chora a morte do filho. Também mencionamos que os militares possuem cores sombrias, ausente de luminosidade. Assim, na categoria cromática, temos a oposição luminosidade versus opacidade.

Nas categorias topológicas e eidéticas, a relação e a posição incrementam os efeitos de sentido deste texto sincrético. A mulher loira, a criança e o homem militar estão quase no centro e, em relação à forma, possuem traços quase retos, enquanto o militar com a espingarda e a mulher gorda, além de estarem agachados, possuem formas arredondadas e curvas. Em comparação ao todo, verificamos a categoria fundamental alto versus baixo, que podem ser sobremodalizadas pelas categorias totalidade versus parcialidade.

Por meio das figuras das duas crianças, o tema da marginalização das periferias ganha destaque, uma vez que a imagem denuncia a crueldade dos policiais ao atirarem numa criança. A outra criança que se encontra nos braços do militar, e que pousa para a foto, tipifica a alienação dos jovens sobre o assunto da ditadura militar. Assim, há um contraste entre vida versus morte. $\mathrm{O}$ tema da desigualdade social também é abordado por meio da linguagem verbo-visual. A intervenção militar, como forma de resolução dos problemas do Brasil, é um tema que nos protestos foi reivindicado pelos manifestantes. A volta da ditadura militar seria uma alternativa de conter a corrupção e os desmandos do atual governo. Nesse cenário, muitas foram as críticas quanto aos manifestantes, uma vez que o pedido de intervenção militar seria uma forma de silenciar toda a população, haja vista que a ditadura foi um rito de 
contenção. O tema do herói militar da ditadura, que salvaria os brasileiros da atual realidade de abandono e corrupção, também foi veiculado na sociedade.

Essa charge mostra o resultado do que acontecerá com a intervenção militar: o militar e sua família serão resguardados enquanto que os demais (no caso, o negro) serão mortos.

Com efeito, ressaltamos que os planos temático-figurativos são a marginalização das periferias, a violência, a intervenção militar, a desigualdade social, o herói militar. Esses planos se interligam, permitindo diversas leituras que ultrapassam os nossos objetivos.

Inicialmente, as manifestações têm como finalidade reivindicar por mudança social, econômica e/ou política. Assim, observando as quatro charges, alguns temas se repetem, como: "impeachment", "intervenção militar", "justiça social”, dentre outros. Comparando-as, cada manifestante representa uma ideologia, especificamente um grupo social, como os manifestantes que tematizam os que querem o retrocesso político ao exigir intervenção militar, por exemplo. Ou ainda, aqueles que aclamam por justiça, mas são um dos agentes da desigualdade social e aqueles que buscam se promover individualmente, sem se importar com o cenário sociopolítico nacional, conhecidos como alienantes.

Verificando a figurativização feminina nas três charges analisadas, na $1^{\mathrm{a}}$ e na $4^{\mathrm{a}}$ charges, ambas loiras ${ }^{17}$, representam a figura feminina manipulada, reforçando a tese de que as mulheres não compreendem a situação política, sendo a minoria que participa ou "dão às costas" para essa realidade. Já a mulher da $2^{\mathrm{a}}$ charge tem os seus propósitos, um deles é reivindicar por justiça, porém não há êxito, pois essa personagem configura a opressão, a injustiça, tornando-se contraditória, ou seja, a ação da personagem não condiz com o que pede na placa. Ainda na $4^{\mathrm{a}}$ charge, há o contraponto entre a figura da mulher loira e a da mulher gorda e negra, esta que figurativiza os desfavorecidos.

Em relação às categorias sincréticas, as três primeiras charges não se constituem de um cenário ou um plano de fundo, mas centralizam as personagens envolvidas em uma manifestação, enquanto a última charge configura um espaço, remetendo a parte focalizada e multicolor com formas retas e pontiagudas ao tempo atual, e a parte obscura com formas arredondadas e curvilíneas ao tempo futuro.

Tanto a $2^{\mathrm{a}}$ como a $3^{\mathrm{a}}$ charge configuram o(a) empresário(a) exercendo o papel de explorador, mesmo estando em uma manifestação, agindo incoerentemente.

Percebemos que, por meio do tema, é possível depreender o valor do sujeito da enunciação (ideologia), ressaltando que as figuras também permitem essa depreensão e, como analisamos um texto sincrético, as diferentes linguagens, que totalizam num significante, podem estabelecer contratos que se complementam ou se contrapõem, visto que, segundo Teixeira, "uma charge pode justamente estar mostrando um choque de pontos de vista" (2008, p. 10). Dessa forma, uma das estratégias enunciativas usadas pelo enunciador nessas charges, se não a principal, é a contradição entre as atitudes e reivindicações das figuras, na linguagem visual e na linguagem verbal, respectivamente, ocasionando incoerência que resulta em humor satirizado e crítico, característica primordial do gênero charge.

\section{Algumas conclusões}

Chegando ao final desta discussão, voltamo-nos para a pergunta que motivou a presente análise: Como as charges abordaram os tipos de pessoas, isto é, os manifestantes que foram às ruas protestar nas cidades brasileiras?

\footnotetext{
${ }^{17}$ A mulher loira figurativiza a ingenuidade e a cultura machista da sociedade brasileira. Essa figura veio à tona em uma música "A loira não é burra", cantada por Frank Aguiar. Além disso, "a mulher loira" foi muito marcada em piadas antes da discussão de "Politicamente correto" e preconceitos, aprofundada pelas mídias e pela sociedade.
} 
Percebemos que as charges, textos sincréticos, abordam vários tipos de pessoas que foram às manifestações e os tipificam como: Manifestantes e manifestantes. Isso significa que dentre alguns manifestantes que lutavam por justiça social, seus comportamentos não condiziam com aquilo que reivindicavam. Assim, é possível perceber que as charges, mesmo sendo de autoria distinta, destacam no discurso que em meio às pessoas que buscam alternativas de mudança, existem também aquelas que usam as manifestações para se promover, ou ainda, utilizam esses protestos na tentativa de realizar seus projetos pessoais.

Além disso, a figura da mulher nas manifestações é estereotipada. Isso indica que parte dos manifestantes, mesmo não apoiando a saída da atual presidente do Brasil, deixaramse contaminar pelo preconceito de que mulher não tem competência para liderar um país. Outro tema amplamente evidenciado nas charges é a presença de empresários e de partidos políticos nesses movimentos, agindo de modo incoerente, como na $3^{\mathrm{a}}$ charge, que nos mostra a exploração por parte do patrão, ao mesmo tempo em que reivindica por justiça. Além disso, o pedido da volta da ditadura militar por alguns demonstra a ausência de informação daqueles que participam desses protestos. Portanto, as charges analisadas apontam para a incoerência dos atos de alguns manifestantes, com algumas figuras da sociedade, que expressam ideologias, atribuindo efeito(s) de sentido que resultam no humor satírico, estilo característico do gênero charge.

\section{REFERÊNCIAS}

BAKHTIN, M. Os gêneros do discurso. In: BAKHTIN, M. Estética da criação verbal. São Paulo: Martins Fontes, 2003, p. 261-306.

BARROS, D. L. P. de. Sintaxe Discursiva. In: BARROS, D. L. P. de. Teoria Semiótica do Texto. São Paulo: Ática, 2002, p. 53-67.

2002, p. 68-69 Semântica Discursiva. In: Teoria Semiótica do Texto. São Paulo: Ática,

ECA. Estatuto da criança e do adolescente. Disponível em:

http://www.crianca.mppr.mp.br/arquivos/File/publi/camara/estatuto_crianca_adolescente_9ed. pdf- Acesso: 24/08/2016

GREIMAS, A. J.; COURTÉS, J. Dicionário de semiótica. São Paulo: Cultrix, 1979.

MARCUSCHI, L. A. Gêneros textuais emergentes no contexto da tecnologia digital. In:

MARCUSCHI, L. A.; XAVIER, A. C. (Org.). Hipertexto e gêneros digitais: novas formas de construção de sentido. Rio de Janeiro: Lucerna, 2004, p. 15-80

PORTELA, J. C.; SCHWARTZMANN, M. N. A noção de gênero em Semiótica. In:

PORTELA, J. C. (org.) [et al.]. Semiótica: identidade e diálogos. São Paulo: Cultura Acadêmica, 2012. p. 69-95.

TEIXEIRA, L. Achados e perdidos: análise semiótica de cartazes de cinema. In: LARA, G. M. P.; MACHADO, I. L.; EMEDIATO, W. (Orgs.) Análise do discurso hoje. Vol. 1. Rio de Janeiro: Nova Fronteira, p. 1-26.

Recebido em 09/08/2017

Aceito em 29/11/2017 